\title{
Analisis Peran Guru Dalam Pemanfaatan Lingkungan Sekolah Terhadap Kreativitas Belajar Siswa
}

\author{
Farhan Saefudin Wahid*', M. Agus Purnomo², Siti Mughimatun Ulya ${ }^{3}$ \\ ${ }^{1,2,3}$ Program Studi Pendidikan Guru Sekolah Dasar, Fakultas Keguruan dan Ilmu Pendidikan, \\ Universitas Muhadi Setiabudi Brebes, Indonesia \\ e-mail: *Ifarhansaefudinwahid@gmail.com, 22aguspurnom.ap1954@gmail.com, \\ sitimuhghimatun@gmail.com
}

\begin{abstract}
ABSTRAK
Penelitian ini dilatarbelakangi oleh pentingnya pemanfaatan lingkungan sekolah untuk mengembangkan kreativitas siswa dalam belajar. Penelitian ini bertujuan untuk mengetahui peran guru dalam pemanfaatan lingkungan sekolah dan dampaknya terhadap kreativitas belajar siswa di SD Islam Losari Lor Brebes. Penelitian ini menggunakan Metode Deskriptif dengan bentuk wawancara kepada kepala sekolah, guru kelas IV, dan peserta didik. Berdasarkan hasil penelitian disimpulkan bahwa pemanfaatan lingkungan sekolah SD Islam Losari Lor Brebes di dalam dan di lingkungan sekolah, dapat membantu kinerja guru dalam menyampaikan informasi dan mempermudah siswa untuk menerima materi dengan cepat dan dapat menumbuhkan kreativitas belajar siswa. Adapun kendala atau kekurangan dalam pemanfaatan lingkungan dalam kelas dan lingkungan sekolah SD Islam Losari Lor Brebes, membutuhkan perencanaan pembelajaran yang matang dan membutuhkan guru pendamping dalam menyampaikan informasi. Saran dari peneliti untuk pihak sekolah agar memperbanyak sumber belajar di dalam lingkungan kelas dan lingkungan sekolah.
\end{abstract}

Kata kunci: pemanfaatan lingkungan sekolah, kreativitas belajar siswa.

\begin{abstract}
The background of this study is motivated by the importance of utilizing the school environment for student creativity in learning which is often forgotten by the teacher as a teacher and educator in a school. This study aims to determine the analysis of teachers in the use of the school environment on student learning creativity at SD Islam Losari Lor Brebes. This research uses descriptive method in the form of interviews with school principals, the Teacher of Four grades and the students. Based on the results of the study concluded that the use of Losari Lor Brebes Islamic Elementary School and the school environment, can help teachers' performance in conveying information and make it easier for students to receive material quickly and can foster student learning creativity. As for obstacles or shortcomings in the use of the environment in the classroom and the Losari Lor Islamic elementary school environment, it requires careful learning planning and requires accompanying teachers to convey information. Suggestions from researchers for the school to increase learning resources in the classroom and school environment.
\end{abstract}

Keywords: utilization of the school environment, student learning creativity.

\section{PENDAHULUAN}

Kegiatan pembelajaran merupakan inti dari proses pendidikan yang sangat menentukan tercapai atau tidaknya tujuan pemebelajaran. Guru diharuskan mampu melaksakan pembelajaran dengan baik sekaligus mengembangkan potensi-potensi yang ada pada peserta didik secara optimal. Upaya untuk mendorong terwujudnya perkembangan potensi siswa tersebut merupakan proses panjang yang tidak dapat diukur dalam periode tertentu. Meskipun demikian, indikator terjadinya perubahan ke arah perkembangan siswa dapat dicermati melalui instrumen pembelajaran yang dapat digunakan guru.

Kegiatan pembelajaran merupakan proses belajar siswa menuju kearah yang lebih baik dalam berperilaku dan berinteraksi dengan lingkungan. Belajar adalah suatu proses perubahan 
Jurnal Ilmiah KONTEKSTUAL, Volume.2, No.01, Agustus 2020, pp. 31-34

tingkah laku individu melalui interaksi dengan lingkungan [1]. Oleh sebab itu, perubahan pembelajaran yang dilakukan harus dilakukan untuk dapat mewujudkan proses belajar dan mengajar yang menyenangkan.

Pembelajaran yang biasa digunakan guru saat ini terkesan monoton, hanya dilakukan didalam ruangan kelas yang harus duduk sopan di bangku, menghadap ke depan mendengarkan keterangan guru, serta melihat papan tulis, sehingga rasa jenuh dan rasa bosan mudah muncul [2]. Pada saat rasa jenuh dan rasa bosan muncul, maka otak sangat sulit menerima penjelasan dari guru. Tentunya, ini berbeda dengan pembelajaran yang diadakan di luar kelas yang dapat memberikan dukungan penuh terhadap proses pembelajaran secara menyeluruh, serta bisa menambah aspek kegembiraan dan kesenangan bagi para siswa dan guru. Oleh sebab itu, lingkungan di sekitar sekolah menawarkan peluang untuk dijadikan sumber belajar [3]. Lingkungan sekitar memperkaya kurikulum.

Berbagai lingkungan yang dapat digunakan untuk sumber belajar antara lain: persawahan, taman, kebun binatang, museum, kerja proyek, dan sebagainya. Kegiatan belajar di luar kelas berupaya memberi semangat kepada anak didik dalam proses belajar mengajar. Adapun arti penting yang bisa diperoleh para siswa dan guru, diantaranya: (1) Dengan belajar di luar kelas, para peserta didik akan dapat beradaptasi dengan lingkungan, alam sekitar, serta dengan kehidupan masyarakat. (2) Para peserta didik bisa mengetahui pentingnya keterampilan hidup dan pengalaman hidup di lingkungan dan alam sekitar. Pasalnya, belajar di luar kelas lebih menuntut kenyataan real yang terjadi [2].

Pada dasarnya, lingkungan adalah situasi di sekitar proses belajar mengajar terjadi [4]. Lingkungan sekolah merupakan sarana bagi siswa, di mana siswa dapat beraktivitas, berekreasi, berinovasi, termasuk mengembangkan pikiran sehingga membentuk perilaku baru dalam kegiatannya. Dengan kata lain lingkungan dapat dijadikan sebagai laboratorium atau tempat bagi siswa untuk bereksplorasi, bereksperimen, dan mengekspresikan diri untuk mendapatkan konsep dan informasi baru sebagai wujud dari hasil belajar. Lingkungan merupakan wadah di mana siswa dapat mengungkapkan seluruh pikiran dan kegiatannya dalam proses pembelajaran.

Lebih lanjut, definisi lain menyebutkan bahwa lingkungan adalah sesuatu yang ada di luar diri individu [5]. Adapun lingkungan pengajaran merupakan segala apa yang bisa mendukung pengajaran itu sendiri yang dapat di fungsikan sebagai sumber pengajaran atau sumber belajar. Bukan hanya guru dan buku/bahan pelajaran yang menjadi sumber belajar. Apa yang di pelajari peserta didik tidak hanya terbatas pada apa yang di sampaikan guru dan apa yang ada dalam textbook. Banyak hal yang dapat di pelajari dan dijadikan sumber belajar peserta didik. Pengajaran yang menhiraulkan lingkungan akan mengakibatkan peserta didik tidak mampu beradaptasi dengan kehidupan yang ia hidup.

Lingkungan adalah segala sesuatu yang ada di sekitar atau di sekeliling siswa (makhluk hidup lain, benda mati, dan budaya manusia) yang dapat di manfaatkan untuk menunjang kegiatan dan pembelajaran secara optimal [6]. Jenis-jenis lingkungan berupa lingkungan sosial dan lingkungan alam/fisik. Penggunaan lingkungan sosial sebagai sumber belajar bisa dimulai dari lingkungan yang terkecil atau paling deket dengan siswa, seperti lingkungan keluarga, lingkungan keluarga, rukun tetangga (RT), rukun warga (RW) dan lain sebagainya (pendekatan semacam ini di sebut expanding community bapproach). Jenis lingkungan lain yang kaya akan informasi adalah lingkungan alam, segala sesuatu yang sifatnya alamiah, seperti sumber daya alam (SDA) seperti air, hutan, tanah dan batu-batuan. tumbuh-tumbuhan (flora), hewan (fauna), sungai, suhu udara, dan sebagainya termasuk dalam lingkungan alam.

Proses pembelajaran mengajarkan siswa untuk menjadi orang yang kreatif dengan memperlihatkan rasa ingin tahu yang besar, konsisten, tidak puas dengan apa yang ada, percaya diri, otonom, bebas dalam pertimbangan, menerima keadaan diri, senang humor, intuitif, dalam berpikir tertarik ada hal yang kompleks, sensitif terhadap rangsangan, toleransi terhadap situasi yang tidak pasti [7]. Kreativitas adalah potensi seseorang untuk memunculkan penemuan baru dalam bidang ilmu dan teknologi serta semua bidang dalam usaha lainnya. Terdapat lima ciri 
kreativitas dalam diri seseorang yaitu kelancaran, keluwesan, keaslian, penguraian, dan perumusan kembali [8]. Kreativitas mempunyai peranan yang sangat penting dalam kehidupan manusia. Melalui kreativitas yang dimilikinya, manusia memberikan bobot dan makna terhadap kehidupan. Secara mikro, kreativitas diwujudkan dalam produk-produk kreatif individu, dan secara makro, kreativitas dimanifestasikan dalam kebudayaan dan peradaban [9].

Observasi awal yang penulis lakukan di SD Islam Losari Lor Brebes, berdasarkan pengamatan penulis sekolah ini termasuk sekolah yang mempunyai lingkungan yang terjaga kebersihan dan kesehatannya serta keadaan lingkungan sekolah yang sangat mendukung sebagai sumber belajar bagi siswa. Halaman sekolah yang cukup hijau tanaman-tanaman yang ada di sekitas sekolah terjaga rapih, proses interaksi siswa dan guru sangat baik, strategi pembelajaran yang di gunakan beragam, guru juga memanfaatkan lingkungan sekolah dalam proses pembelajaran dan mengajak siswa untuk menumbuhkan kreativitas belajar siswa.

Pemanfaatan lingkungan sekolah sebagai salah satu sumber belajar siswa diharapkan dapat meningkatkan pengalaman dan ilmu pengetahuan siswa secara mendalam, serta dengan didukung adanya kreativitas guru dalam memilih media ini sebagai sumber belajar siswa selain sumber belajar yang ada di dalam kelas. Sumber belajar dari lingkungan ini diharapkan mampu menumbuhkan kecakapan dan kepandaian yang dapat diterapkan siswa dalam masyarakat dengan mempelajari secara langsung keadaan nyata dan segala hal yang ada disekitarnya. Jadi, sangatlah penting disini untuk para guru SD Islam Losari Lor mengembangkan kreativitaasnya dalam memilih metode dan sumber belajar dalam proses pembelajaran.

Berdasarkan konteks penelitian yang telah dijelaskan diatas, peneliti tertarik untuk melakukan penelitian tentang Analisis Peran Guru dalam Pemanfaatan Lingkungan Sekolah Terhadap Kreativitas Belajar Siswa SD Islam Losari Lor Brebes. Tujuan penelitian ini adalah sebagai berikut. 1) untuk mengetahui pemanfaatan lingkungan dalam kelas terhadap kreativitas belajar siswa; 2) untuk mengetahui pemanfaatan lingkungan sekolah terhadap kreativitas belajar siswa; dan 3) untuk mengetahui kendala-kendala guru dalam pemanfaatan lingkungan dalam kelas dan lingkungan sekolah terhadap kreativitas belajar siswa.

\section{METODOLOGI PENELITIAN}

Penelitian ini menggunakan pendekatan kualitatif dengan jenis penelitian deskriptif studi kasus. Lokasi penelitian dilaksanakan di SD Islam Losari Lor Brebes yang beralamat di desa losari lor kecamatan losari kabupaten brebes. Waktu penlitian dilaksanakan pada bulan Agustus sampai Januari 2019. Desain penelitian ini adalah studi kasus tentang analisis guru dalam pemanfaatan lingkungan sekolah terhadap kreativitas belajar siswa SD Islam Losari Lor Brebes. Sumber-sumber data dalam penelitian ini adalah sebagai berikut. 1) informan, 2) arsip atau dokumentasi. Fokus penelitian peneliti adalah analisis peran guru dalam memanfaatkan lingkungan terhadap kreativitas belajar siswa di kelas IV SD Islam Losari Lor Brebes.

Teknik pengumpulan data yang di gunakan pada penelitian ini adalah sebagai berikut: 1) observasi, 2) wawancara, 3) dokumentasi. Uji keabsahan data untuk mendapatkan kreadibilitas peneliti menggunakan triangulasi teknik.

\section{HASIL DAN PEMBAHASAN}

\section{Hasil Penelitian}

Berdasarkan dari rumusan masalah dan indikator dalam penelitian yang telah dilakukan dengan metode observasi, wawancara dan dokumentasi, maka di paparkan tentang Analisis Guru dalam Pemanfaatan Lingkungan Sekolah Terhadap Kreativitas Belajar Siswa SD Islam Losari Lor Brebes. Hasil wawancara merupakan hasil yang diperoleh melalui wawancara dengan informen atau narasumber, informan dalam penelitian ini adalah kepala sekolah, guru kelas IV 
Jurnal Ilmiah KONTEKSTUAL, Volume.2, No.01, Agustus 2020, pp. 31-34

dan siswa kelas IV SD Islam Losari Lor Brebes. Pemanfaatan Lingkungan dalam kelas Terhadap Kreativitas Belajar Siswa dapat mempercepat laju belajar, mengurangi beban guru dalam menyajikan informasi sehingga mudah bagi siswa untuk menerima materi yang diberikan guru, karena dapat memanfaatkan alat peraga yang berada didalam kelas. Ketika siswa belajar dengan memanfaatkan lingkungan sekolah, siswa sangat antusias dalam pembelajaran, motivasi belajar siswa tumbuh dan adanya interaksi yang baik antara siswa dan guru, siswa dan siswa.

Pemanfaatan Lingkungan Sekolah Terhadap Kreativitas Belajar Siswa. lingkungan sekolah dengan menghadapkan siswa untuk belajar berdasar dari lingkungan yang nyata sebagai sumber belajar, menumbuhkan kreatifitas belajar siswa bukan hanya pada saat proses pembelajaran saja, melainkan juga dapat di ingat sebagai wujud pengamalan untuk pembelajaran kedepannya, Pembelajaran dalam pemanfaatan lingkungan sekolah juga memperkaya pengetahuan yang tidak terbatas dan kegiatan pembelajaran lebih bermakna serta pemanfaatan lingkungan sekolah dapat disesuaikan dengan materi pembelajaran, dan pemanfaatkan lingkungan sekitar seperti ruang perpustakaan, ruang komputer, musholah, green house, dan halaman sekolah sebagai objek pembelajaran memberikan pemahaman nyata.

\section{Pembahasan}

Sebagai guru yang faham mengenai kebutuhan siswa, guru berusaha untuk menyajikan materi agar siswa antusias dalam pembelajaran, memanfaatkan lingkungan sekolah sebagai sumber belajar adalah cara guru untuk dapat menyampaikan materi dengan baik. Dalam hal ini pemanfaatan lingkungan sekolah terhadap kreativitas belajar siswa dalam kelas, dapat menumbuhkan ide-ide kreatif siswa. Misalnya ketika pembelajaran muatan Matematika materi Bangun Ruang, guru menunjukan contoh benda berbentuk bangun ruang yang terdapat didalam kelas, secara spontan siswa menyebutkan benda-benda lain yang berbentuk bangun ruang selain yang terdapat didalam kelas.

Pembelajaran berbasis lingkungan sekolah dengan menghadapkan siswa untuk belajar berdasar dari lingkungan yang nyata sebagai sumber belajar. Sebuah penelitian menyebutkan bahwa praktik lapangan di lingkungan sekitar, merupakan salah satu cara untuk dapat mengembangkan nilai karakter dalam diri peserta didik [10]. Melalui lingkungan siswa akan mengamati hal-hal yang berkaitan dengan materi yang sedang berjalan dan menghubungkan dengan proses pembelajaran. Berdasarkan kegiatan tersebut akan menumbuhkan kreatifitas belajar siswa bukan hanya pada saat proses pembelajaran saja, melainkan juga dapat di ingat sebagai wujud pengamalan untuk pembelajaran kedepannya. Pembelajaran dalam pemanfaatan lingkungan sekolah juga memperkaya pengetahuan yang tidak terbatas dan kegiatan pembelajaran lebih bermakna serta pemanfaatan lingkungan sekolah dapat disesuaikan dengan materi pembelajaran, dan pemanfaatkan lingkungan sekitar seperti ruang perpustakaan, ruang komputer, mushola, green house, dan halaman sekolah sebagai objek pembelajaran memberikan pemahaman nyata dan memicu kemandirian siswa dalam belajar dan kaitannya dengan kehidupan.

Keterbatasan sumber belajar seperti alat peraga, media dan lain sebagainya dalam kelas yang dapat di manfaatkan oleh guru dalam pembelajaran, pembelajaran terlihat monoton karena siswa sering menjumpai sumber belajar yang di manfaatkan dalam pemanfaatan lingkungan sekolah di dalam kelas, Adapun kekurangan dalam pemanfaatan lingkungan sekolah sulitnya mengatur kondisi siswa agar fokus pada guru dalam menyampaikan materi saat pembelajaran menggunakan halaman sekolah, serta memerlukan adanya guru tambahan atau guru pembimbing. Pemanfaatkan lingkungan sekolah membutuhkan perencanaan yang matang seperti halnya menentukan tujuan belajar yang behubungan dengan pembahasan bidang study tertentu, menentukan objek yang harus dipelajari, menentukan cara berfikir siswa saat pemanfaatan lingkungan sekolah serta mempersiapkan teknis untuk kegiatan belajar. 


\section{SIMPULAN}

Pemanfaatan lingkungan dalam kelas SD Islam Losari Lor Brebes, dapat membantu guru dalam menyampaikan materi atau informasi pembelajaran sehingga dapat menumbuhkan antusias siswa yang baik, serta dapat menumbuhkan ide-ide kreatif siswa dalam belajarnya. Serata menjalin hubungan baik antara siswa dengan siswa maupun siswa dengan guru.

Pemanfaatan lingkungan sekolah SD Islam Losari Lor Brebes, menghadapkan siswa untuk belajar berdasar dari lingkungan yang nyata, Pemanfaatan lingkungan sekolah sangat dinantikan oleh siswa dan juga dapat menumbuhkan kreativitas belajar siswa dan memberikan pengalaman belajar bagi siswa untuk memperluas wawasan mereka mengenai materi yang di ajarkan.

Kendala guru dalam pemanfaatkan lingkungan dalam kelas dan lingkungan sekolah terhadap kreativitas belajar siswa, membutuhkan guru pendamping untuk mengarahkan siswa agar dapat fokus pada pembelajaran, lingkungan sekolah sebagai sumber belajar di dalam kelas sangat terbatas namun dalam penerapannya lebih mudah karena pandangan siswa lebih dapat di fokuskan dibanding dengan sumber belajar di lingkungan sekolah lainnya.

Pemanfaatan lingkungan sekolah di dalam kelas, sebaiknya guru mempersiapkan dengan matang, guru dapat mengkonfirmasikan kepada kepala sekolah agar dapat melengkapi sumber belajar di dalam kelas. Pemanfaatan lingkungan sekolah, sebaiknya guru mempersiapkan agar pembelajaran dapat berjalan efektif dan dapat meminta bantuan kepada guru lain yang sedang tidak bertugas. Pemanfaatan lingkungan sekolah dalam pembelajaran hendaknya guru dapat meminimalisir kendala-kendala yang akan terjadi dengan mempersiapkan secara matang proses pembelajaran yang akan dilaksanakan.

\section{REFERENCES}

[1] Hamalik, O., Proses Belajar Mengajar, 2001, Bumi Aksara, Jakarta.

[2] Vera, A., Metode Mengajar Anak di Luar Kelas, 2012, Divaperss, Yogyakarta.

[3] Kurniasih, I., Ragam Pengembangan Model Pembelajaran untuk Peningkatan Profesionalisme Guru, 2017, Katapena, Jakarta.

[4] Sangidun, Kampus Kawasan Lingkungan, 2010, Saka, Yogyakarta.

[5] Rohani, A., Pengelolaan Pengajaran, 2010, Rineka Cipta, Jakarta.

[6] Wahid, FS., Pendidikan IPS di SD Untuk PGSD (S1), 2015, Diya Media Group, Brebes.

[7] Anas, I., Pendidikan Karakter, Pendidikan Berbasis Agama Dan Budaya Bangsa, 2013, Pustaka Setia, Bandung.

[8] Saondi, O \& Suherman, A., Etika Profesi Keguruan, 2012, Refika Aditama, Bandung.

[9] Murniyati, E., Pendidikan Pembimbingan Anak Kreatif, 2012, Pedagogia, Yogyakarta.

[10] Mumpuni, A., \& Masruri, M. S, Muatan Nilai-Nilai Karakter Pada Buku Teks Kurikulum 2013 Pegangan Guru Dan Pegangan Siswa Kelas II. Jurnal Pendidikan Karakter, vol. 6, no. 1, pp. 17-28, 2016, [Online]. Available: https://journal.uny.ac.id/index.php/jpka/article/view/10728/8084 